\title{
Glucocorticoid maturation of mitochondrial respiratory capacity in skeletal muscle before birth
}

\author{
K L Davies', E J Camm1,2, D J Smith1, O R Vaughan1,3, A J Forhead1,4, A J Murray1 and A L Fowden'1 \\ 1Department of Physiology, Development and Neuroscience, University of Cambridge, Cambridge, UK \\ ${ }_{2}^{2}$ The Ritchie Centre, Hudson Institute of Medical Research, Clayton, Australia \\ 3Institute for Women's Health, University College London, London, UK \\ ${ }^{4}$ Department of Biological and Medical Sciences, Oxford Brookes University, Oxford, UK
}

Correspondence should be addressed to A L Fowden: alf1000@cam.ac.uk

\begin{abstract}
In adults, glucocorticoids act to match the supply and demand for energy during physiological challenges, partly through actions on tissue mitochondrial oxidative phosphorylation (OXPHOS) capacity. However, little is known about the role of the natural prepartum rise in fetal glucocorticoid concentrations in preparing tissues for the increased postnatal energy demands. This study examined the effect of manipulating cortisol concentrations in fetal sheep during late gestation on mitochondrial OXPHOS capacity of two skeletal muscles with different postnatal locomotive functions. Mitochondrial content, biogenesis markers, respiratory rates and expression of proteins and genes involved in the electron transfer system (ETS) and OXPHOS efficiency were measured in the biceps femoris (BF) and superficial digital flexor (SDF) of fetuses either infused with cortisol before the prepartum rise or adrenalectomised to prevent this increment. Cortisol infusion increased mitochondrial content, biogenesis markers, substrate-specific respiration rates and abundance of ETS complex I and adenine nucleotide translocator (ANT1) in a muscle-specific manner that was more pronounced in the SDF than BF. Adrenalectomy reduced mitochondrial content and expression of $P G C 1 \alpha$ and ANT1 in both muscles, and ETS complex IV abundance in the SDF near term. Uncoupling protein gene expression was unaffected by cortisol manipulations in both muscles. Gene expression of the myosin heavy chain isoform, MHCIIX, was increased by cortisol infusion and reduced by adrenalectomy in the BF alone. These findings show that cortisol has a muscle-specific role in prepartum maturation of mitochondrial OXPHOS capacity with important implications for the health of neonates born pre-term or after intrauterine glucocorticoid overexposure.
\end{abstract}

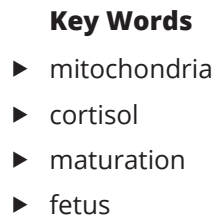

Journal of Endocrinology (2021) 251, 53-68

\section{Introduction}

In adults, glucocorticoids are stress hormones with metabolic actions on a wide range of tissues that maintain functions critical to survival in adverse environmental conditions and during normal physiological challenges to homeostasis-like exercise and pregnancy (Picard et al. 2018, Bartho et al. 2020, Casuro \& Huertus 2020). Many of these functions require energy in the form of ATP, which is produced mainly by oxidative phosphorylation (OXPHOS) 
in the mitochondria (Nunnari \& Suomalainen 2012, Rodriguez-Cano et al. 2020). Mitochondria, therefore, have a key role in the response to both internal and external environmental cues and are known to be regulated by glucocorticoids in adulthood (Lee et al. 2013, Lapp et al. 2019).

Mitochondria are dynamic organelles that respond to changes in energy demand by biogenesis, fusion/ fission and by alterations in the abundance of the electron transfer system (ETS) complexes and other proteins regulating ATP production (Goffat \& Wiesner 2003, Liang \& Ward 2006, Chandhol et al. 2018). Utilising a range of metabolic substrates, ATP is produced by ATP synthase using the proton gradient across the inner mitochondrial membrane generated by redox reactions at ETS complexes with oxygen as the final electron acceptor. The efficiency of mitochondrial OXPHOS also depends on uncoupling proteins (UCPs) that dissipate the proton gradient when activated, and on transporters that shuttle adenine nucleotides across the mitochondrial membranes (Kimura \& Rasmussen 1977, Nunnari \& Suomalainen 2012). Glucocorticoids have been shown to influence many of these regulatory processes in mitochondria of several adult tissues, including skeletal muscle (Djouadi et al. 1994, Rachamim et al. 1995, Weber et al. 2002, Du et al. 2009).

Glucocorticoids can also act as stress signals in the fetus but, during normal conditions in late gestation, their primary role is as a signal of impending delivery (Reynolds 2013, Fowden \& Forhead 2015). In most mammals studied to date, fetal glucocorticoid concentrations rise naturally towards term and switch fetal tissues from growth to differentiation in preparation for birth (Fowden et al. 1998). This prepartum glucocorticoid surge also activates many processes that have little or no function in utero but which are essential for neonatal survival such as breathing, thermogenesis, glucogenesis and locomotion (Fowden et al. 2016). All these new functions require extra energy but relatively little is known about the effects of glucocorticoids on mitochondrial function in fetal tissues during late gestation, particularly in species that are mobile from birth.

In several species, mitochondrial function is known to rise between fetal and neonatal life in several different tissues (Prieur et al. 1998, Lehman et al. 2000, Nakai et al. 2002, Minai et al. 2008, Rog-Zielinska et al. 2015, Davies et al 2020). Administration of potent synthetic glucocorticoids during rodent pregnancy has also been shown to affect the abundance of mitochondrial proteins in fetal tissues near term (Nakai et al. 2002, Prieur et al. 1998,
Rog-Zielinska et al. 2015). In addition, a recent study in fetal sheep has demonstrated that the natural prepartum cortisol surgeclosely parallels the increase in mitochondrial OXPHOS capacity of skeletal muscle towards term (Davies et al. 2020). However, whether these changes are the direct consequence of the fetal cortisol increment remains unknown. This study, therefore, examined the hypothesis that cortisol causes maturation of mitochondrial OXPHOS capacity in skeletal muscle towards term.

\section{Methods}

\section{Animals}

A total of 24 time-mated pregnant ewes and 6 newborn twin lambs were used in this study. Of the pregnant ewes, 12 carried single fetuses while the remainder were twinbearing. Pregnant ewes were group-housed before surgery and singly housed within sight and sound of other sheep after surgery. They had free access to hay and water at all times except for 12-18 $\mathrm{h}$ before surgery when food was withheld. All animal procedures were carried out under the UK Animals (Scientific Procedures) Act 1986 Amendment Regulations 2012 following ethical review by the University of Cambridge Animal Welfare and Ethical Review Body.

\section{Surgical procedures}

Between 114 and 119 days of gestational age (dGA), surgery was carried out on 6 twin-bearing and 12 single-bearing ewes under isofluorane anaesthesia (1.5-2\% in 5:1 $\mathrm{O}_{2}: \mathrm{N}_{2} \mathrm{O}$ mixture) with positive pressure ventilation. In twinbearing ewes, one fetus was adrenalectomised (AX) and its twin was sham-operated as a control (Barnes et al. 1978). In the single-bearing ewes, catheters were inserted into the maternal dorsal aorta and the fetal dorsal aorta and caudal vena cava, via the femoral vessels, and exteriorised through the maternal flank (Fowden \& Silver 1995). The ewes were monitored throughout surgery using a capnograph and pulse oximeter. At surgery, the ewes were given antibiotics (oxytetracycline, $20 \mathrm{mg} / \mathrm{kg}$ i.m., Allamycin, Norbrook Laboratories, Newry, UK and penicillin, Depocillin, Intervet international, Milton Keynes, UK, $15 \mathrm{mg} / \mathrm{kg}$ i.m. to mother and intra-amniotically or i.v. to fetus) and analgesia (1 mg/kg carprofen, s.c. Rimadyl, Zoetis, London UK). Penicillin treatment to the ewe continued for 2 days post-operatively.
This work is licensed under a Creative Commons Attribution 4.0 International License.

ded from Bioscientifica.com at 04/26/2023 11:25:25AM 


\section{Experimental procedures}

All catheterised animals were sampled daily to maintain catheter patency and to collect blood samples to measure blood gases and concentrations of metabolites and hormones. Following post-operative recovery for at least 5 days, the catheterised fetuses were assigned randomly to receive a 5 -day i.v. infusion of either saline $(0.9 \% \mathrm{NaCl}$, $3 \mathrm{~mL} /$ day, $n=6$, control, 3 male M: 3 female F) or cortisol (2-3 mg/kg/day Solu-Cortef; Pharmacia, $n=6,4 \mathrm{M}: 2 \mathrm{~F})$. At the end of infusion (128-131 dGA), the ewes and fetuses were killed by administration of a lethal dose of anaesthetic (200 mg/kg sodium pentobarbitone, iv, Pentoject, Animalcare Ltd, York, UK) and tissues collected from the fetus. Similarly, at 141-145 dGA, the ewes with AX (4M:2F) and sham-operated fetuses (2M:4F) were euthanised with an overdose of anaesthetia as above and the fetuses were delivered in random order. A blood sample was taken from the umbilical artery of each fetus before administration of a lethal dose of sodium pentobarbitone $(200 \mathrm{mg} / \mathrm{kg})$ and tissue collection. At delivery, the two female AX fetuses had small adrenal remnants (80 mg and $180 \mathrm{mg}$ ) so neither was used for any subsequent analyses.

Umbilical arterial blood and skeletal muscle were also collected from twin fetuses of six unoperated ewes at 102-105 dGA as described above. Tissue from only one fetus of each pair (2M:4F) was randomly selected for further study. In addition at 1-2 days of postnatal age, one lamb from six unoperated pairs of twins (3M:3F) was euthanised for tissue collection using sodium pentobarbitone (200 $\mathrm{mg} / \mathrm{kg}$ ) after collection of a blood sample from the jugular vein. All blood samples were collected into heparincoated tubes and, after centrifugation, the plasma was stored at $-20^{\circ} \mathrm{C}$ for future hormone analysis. Immediately following euthanasia, the fetal and newborn lambs were weighed and measured.

Two hindlimb skeletal muscles with different postnatal functions in locomotion, the biceps femoris (BF) and superficial digital flexor (SDF), were immediately collected and weighed. The BF is a large powerful, multifunctional muscle producing mechanical power by shortening while the SDF is a small flexor muscle generating force predominately by isometric contraction (Fourie 1962, Biewener 1998). The BF controls locomotive gait through extension and abduction of the hindlimb whereas the SDF controls foot placement important for allowing the neonate to stand (Fourie 1962, Walker \& Luff 1995). Both muscles are of mixed fibre type with a combination of slow-twitch type I and fast-twitch type II fibres (Davies 2018). In late gestation, the SDF has proportionally more type I fibres than the BF, although both muscles still contain undifferentiated fibres at birth (Davies 2018, Davies et al. 2020).

Samples of these muscles were snap-frozen in liquid nitrogen before being stored at $-80^{\circ} \mathrm{C}$ until required. Additionally, in the fetuses at 129 and 144 dGA, a small sample $(\approx 100-200 \mathrm{mg}$ ) from the centre of each muscle was collected into ice-cold biopsy preservation solution (BIOPS; pH 7.1 solution containing $2.77 \mathrm{mM} \mathrm{CaK}_{2}$ EGTA, $7.23 \mathrm{mM} \mathrm{K} \mathrm{K}_{2}$ EGTA, $20 \mathrm{mM}$ imidazole, $20 \mathrm{mM}$ taurine, 50 $\mathrm{mM}$ MES, $0.5 \mathrm{mM}$ dithiothreitol, $6.56 \mathrm{mM} \mathrm{MgCl}_{2} \cdot \mathrm{H}_{2} \mathrm{O}$, $5.77 \mathrm{mM} \mathrm{Na}_{2}$ ATP and $15 \mathrm{mM}$ phosphocreatine; Pesta \& Gnaiger 2012) before dissection for respirometry.

\section{Respirometry}

Respirometry measurements were made on the skeletal muscle samples from the AX, sham-operated, cortisoland saline-infused groups of fetuses using the protocol described previously for this tissue (Kuznetsov et al. 2008, Pesta \& Gnaiger 2012). Briefly, 2-3 mg pieces of tissue were dissected in BIOPS, bundles of 6-8 fibres were teased apart before incubating with saponin for $20 \mathrm{~min}$ to permeabilise the plasma membrane (100 $\mu \mathrm{g}$ saponin/ $\mathrm{mL}$ BIOPS). Samples were transferred into an isotonic respiration medium maintained at $37^{\circ} \mathrm{C}$ (MiR05; pH7.1 solution containing $20 \mathrm{mM}$ HEPES, $0.5 \mathrm{mM}$ EGTA, $3 \mathrm{mM} \mathrm{MgCl} \cdot 6 \mathrm{H}_{2} \mathrm{O}, 10 \mathrm{mM} \mathrm{KH_{2 }} \mathrm{PO}_{4}, 20 \mathrm{mM}$ taurine, $110 \mathrm{mM}$ sucrose, $60 \mathrm{mM}$ K-lactobionate and 1g/1 BSA; Pesta \& Gnaiger 2012, Gnaiger et al. 2000) in order to measure oxygen $\left(\mathrm{O}_{2}\right)$ consumption using Clark-type oxygen electrodes (Strathkelvin Instruments, Glasgow, UK). Substrates were added into the chambers at saturating concentrations according to three protocols as previously described (Davies et al. 2020). Malate (2 mM), glutamate (10 $\mathrm{mM}), \operatorname{ADP}(10 \mathrm{mM})$ and succinate $(10 \mathrm{mM})$ were added in sequence to give a measure of maximal ADPcoupled oxygen consumption when electron entry to both complexes I and II of the ETS is saturated. The second protocol involved the addition of malate $(2 \mathrm{mM})$, pyruvate (5 mM) and ADP (10 mM) was used to obtain a measure of oxidative capacity for pyruvate (Py), a derivative of glucose. Thirdly, malate $(2 \mathrm{mM})$, palmitoyl-carnitine (PC, $40 \mu \mathrm{M})$ and ADP $(10 \mathrm{mM})$ were added to provide a measure of fatty acid oxidation capacity. In all protocols, leak state was measured in the presence of substrates before the addition of ADP, and the experiment concluded with the addition of cytochrome c $(10 \mu \mathrm{M})$ to check outer mitochondrial membrane integrity. Results were excluded 
if there was a $\geq 15 \%$ increase in $\mathrm{O}_{2}$ consumption following cytochrome c addition. Additionally, data were excluded if the rate of $\mathrm{O}_{2}$ uptake over the baseline period before substrates were added, exceeded $0.001 \mu \mathrm{mol} \mathrm{O}_{2} / \mathrm{min}$ as this suggests insufficient plasma membrane permeabilisation (Kuznetsov et al. 2008). Following respirometry, muscle fibres were extracted from chambers and dried for $48 \mathrm{~h}$ before being weighed, and results are presented as $\mathrm{O}_{2}$ consumption/mg dry weight.

\section{Biochemical analyses}

\section{Hormone assays}

Plasma cortisol concentrations were measured using a human ELISA (RE52061, Tecan, Männedorf, Switzerland), previously validated for sheep plasma (Vaughan et al. 2016). Intra- and inter-assay coefficients of variation for the cortisol assay were 3 and 5\%, respectively, and the limit of detection was $5.2 \mathrm{ng} / \mathrm{mL}$. Because cortisol increases fetal $\mathrm{T}_{3}$ concentrations towards term and thyroid hormones are known to affect $\mathrm{O}_{2}$ consumption by fetal tissues (Fowden \& Silver 1995, Forhead et al. 2006, Davies et al. 2020, 2021), total plasma $T_{3}$ and $T_{4}$ were also measured using radioimmunoassays (Kit numbers, 06B254215 and 06B 254011, respectively, MP Biomedical, Eschwege, Germany), previously validated for sheep plasma (Fowden $\&$ Silver 1995). Intra- and inter-assay variations were less than 2 and $8 \%$ for $\mathrm{T}_{3}$ and 3 and $5 \%$ for $\mathrm{T}_{4}$. The limit of detection was $0.14 \mathrm{ng} / \mathrm{mL}$ for $\mathrm{T}_{3}$ and $11.3 \mathrm{ng} / \mathrm{mL}$ for $\mathrm{T}_{4}$.

\section{Biochemical composition}

Water content was calculated as a percentage by weighing, freeze-drying overnight and then re-weighing samples of frozen muscles. Following extraction from homogenised frozen tissue, protein content was measured using a bicinchoninic acid assay and expressed as mg protein per gram tissue (wet weight) or as mg protein per mg dry weight calculated using the percentage water content of the muscle.

\section{Citrate synthase activity}

Activity of citrate synthase (CS), an enzyme of the tricarboxylic acid cycle, is a putative marker of muscle mitochondrial content (Larsen et al. 2012) and was measured spectrophotometrically in the skeletal muscles. Ten to thirty micrograms of homogenised protein was added to the assay buffer ( $\mathrm{pH}$ 8) containing $0.1 \mathrm{mM}$ 5,5'-Dithio-bis(2-nitrobenzoic acid), DTNB, $1 \mathrm{mM}$ oxaloacetate and $0.3 \mathrm{mM}$ acetyl-CoA. CS activity was determined as the maximal rate of absorbance change at $412 \mathrm{~nm}$ over $3 \mathrm{~min}$ (a measure of the rate of 5-thio-2nitrobenzoic acid production). CS activity is expressed as per mg protein.

\section{Western blotting}

Frozen muscle samples (55 $\mathrm{mg} \pm 10 \%$ ) were homogenised, total protein extracted and diluted to $2.5 \mu \mathrm{g} / \mu \mathrm{L}$ in $8 \%$ SDS solution. Protein was electrophoresed on a $12 \%$ polyacrylamide gel, transferred to a nitrocellulose membrane and stained with Ponceau-S to allow for normalisation of protein loading. Membranes were incubated either with primary antibodies to ETS complexes I-IV and ATP synthase (OXPHOS antibody cocktail; 458099; Life Technologies; 1:1000), followed by an HRP-linked anti-mouse secondary antibody (NIF82; GE Healthcare; 1:5000) or to ANT1 (Abcam, ab1002032, 1:1000), followed by HRP-linked donkey anti-rabbit IgG (GE healthcare; NA934V, 1:5000). ECL was used to visualise protein bands and quantified using ImageJ (http://rsb.info.nih.gov/ij/).

\section{qRT-PCR}

Frozen skeletal muscle samples were powdered and RNA extracted using TRIzol (Thermo Fisher) and chloroform, and the aqueous phase used in the RNeasy Plus kit (Qiagen). RNA concentration was measured using a Nanodrop ND-1000 spectrophotometer, diluted to $50 \mathrm{ng} / \mu \mathrm{L}$ and used for cDNA synthesis (High Capacity cDNA RT Kit; Applied Biosystems). qRT-PCR was performed using a MESA BLUE Mastermix (Eurogentec, Liège, Belgium) following the manufacturer's recommended protocol (5 min at $95^{\circ} \mathrm{C}$ followed by 40 amplification cycles of $15 \mathrm{~s}$ at $95^{\circ} \mathrm{C}$ and $1 \mathrm{~min}$ at $60^{\circ} \mathrm{C}$ ). The genes assayed, their encoded protein and function together with the primer sequences used are given in Table 1 . Results were analysed using $2-\Delta \Delta \mathrm{Ct}$ method (Schmittgen \& Livak 2018) and expressed relative to the geometric mean of S15 and 18S housekeeper genes and set relative to the average of the relevant control group. All samples were run in triplicate and housekeeper gene expression did not differ significantly between groups.

\section{Statistical analyses}

Data are presented as mean \pm S.E.M., and GraphPad Prism Version 6.05 (www.graphpad.com) was used for analyses. A one-way ANOVA was used to assess the developmental changes in CS and plasma cortisol concentration data followed by Tukey's multiple comparison post hoc test. A $t$-test or non-parametric Mann-Whitney test, as appropriate, was used to compare the data between sham-operated and AX and between cortisol- and saline-infused fetuses.

This work is licensed under a Creative Commons Attribution 4.0 International License. 
Table 1 Forward and reverse primer sequences used for SYBR qRT-PCR.

\begin{tabular}{l} 
Target gene, encoded protein and function \\
\hline Ribosomal protein S15 (RPS15) \\
18S rRNA \\
Peroxisome proliferator-activated receptor gamma \\
coactivator 1 alpha (PPARGC1A) \\
PGC1 $\alpha$ protein \\
Regulator of Mitochondrial biogenesis \\
Mitofusin 2 (MFN2) \\
MFN2 protein \\
Regulator of mitochondrial membrane fusion \\
Dyamin-related protein1 (DRP1) \\
DRP1 protein \\
Regulator of mitochondrial membrane fission \\
Uncoupling protein 2 (UCP2) \\
UCP2 protein \\
Mitochondrial uncoupling \\
Uncoupling protein 3 (UCP3) \\
UCP3 protein \\
Mitochondrial uncoupling \\
SLC25A4 \\
Adenine nucleotide translocase 1 (ANT1) protein \\
Transport of ADP and ATP across mitochondrial \\
membranes. Mild mitochondrial uncoupling \\
Myosin heavy chain 7 (MHY7) \\
MHCI protein \\
Muscle contraction \\
MHY2 \\
MHCIla protein \\
Muscle contraction \\
MHY1 \\
MHCIlx protein \\
Muscle contraction \\
\hline
\end{tabular}

\begin{tabular}{|c|c|}
\hline Primer sequences & Reference \\
\hline $\begin{array}{l}\text { F: ATCATTCTGCCCGAGATGGTG } \\
\text { R: TGCTTCACGGGCTTGTAGGTG }\end{array}$ & Yates et al. 2016 \\
\hline $\begin{array}{l}\text { F: GTAACCCGTTGAACCCCATT } \\
\text { R: CCATCCAATCGGTAGTAGCG }\end{array}$ & Byrne et al. 2010 \\
\hline
\end{tabular}

F: GAGATGTGACCACCGAGAATGAG

R: GCTGTTGACAAATGCTCTTCGC

R: CACCGCCGAATAATTCACTT

F: CATCAGCTATACTGGCTCCAACT

R: AATGAGCAAAAGTCCCAGACA

F: ATGCCAGCAAGTCCACAGAA

R: TGTTCTCGGGCAGACAGTTT

F: AAGGCCCACCTAATGACAGA

R: CCCAGGGCAGAGTTCATGT

F: GAAAGGAATTCTGCCCAACA

R: TCCAAAGGCAGAGACGAAGT

F: TGGTGTCCTACCCCTTTGAC

R: CAGGCGCCTTTGAAGAAAGC

Myers et al. 2008

Davies et al. 2020

Reddy et al. 2016

Davies et al. 2020

Kelly et al. 2011

Kelly et al. 2011

F: GAGATGGCCGCGTTTGGGGAG

R: GGCTCGTGCAGGAAGGTCAGC

Yates et al. 2016

F: ACCGAAGGAGGGGCGACTCTG

R: GGCTCGTGCAGGTGGGTCATC

Yates et al. 2016

F: AAAGCGACCGTGCAGAGCAGG R: GGCTCGTGCAGGTGGGTCATC

Yates et al. 2016
Where appropriate, a $t$-test of the significance of a single mean was used to assess the mean difference between the AX and sham-operated twin pairs. Pearson's correlation coefficient was used to assess correlations between variables and log-transformed hormone concentrations. Partial correlation analysis was applied to determine the relationship between two variables controlling for a third. $P \leq 0.05$ was considered significant throughout.

\section{Results}

\section{Hormone concentrations, morphometry and body composition}

In line with previous findings (Barnes et al. 1978, Fowden et al. 1998), cortisol concentrations increased in control animals towards term and on into the immediate neonatal period (Fig. 1A). Relative to saline-infused fetuses at 129 dGA, cortisol infusion significantly increased the cortisol concentration to values similar to those seen in the older sham-operated controls at 144 dGA (Fig. 1A). In contrast, AX prevented the normal prepartum rise in fetal cortisol concentrations; the mean value in AX fetuses was significantly lower than the concentrations in shamoperated controls at $144 \mathrm{dGA}$ and similar to control values at the earlier gestational ages (Fig. 1A). Fetal plasma $T_{3}$ concentrations were significantly higher in cortisol - than saline-infused fetuses but were not significantly affected by AX, although values had a tendency to be lower in the AX than sham-operated fetuses $(P=0.057$, Table 2$)$. There were no changes in fetal plasma $\mathrm{T}_{4}$ concentrations with cortisol infusion or AX (Table 2).

Neither cortisol infusion nor AX had a significant effect on fetal morphometric measurements or muscle weights compared with their respective controls (Table 2). Water content was significantly lower in the BF of cortisol-infused than saline-infused fetuses at 129 dGA and significantly higher in both muscles of AX compared 
A
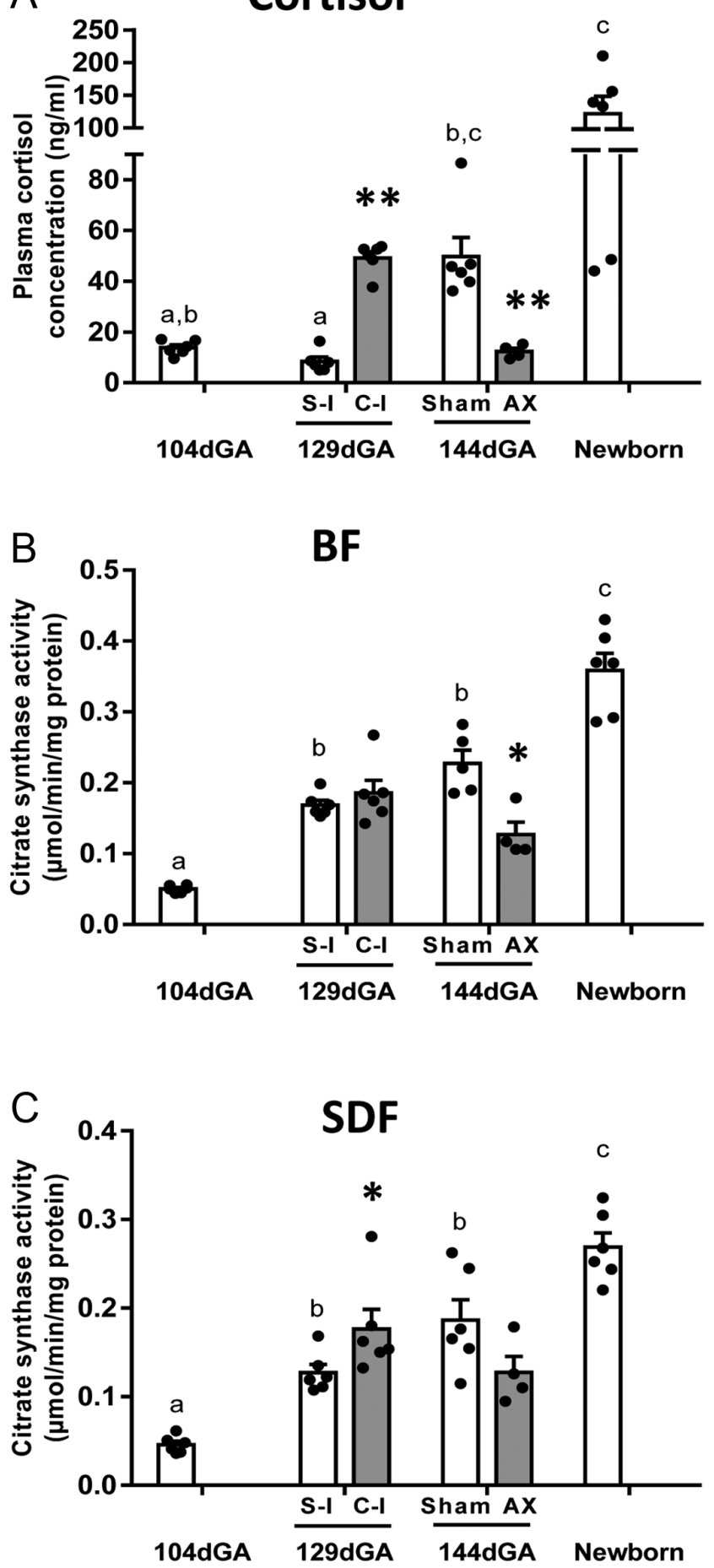

Figure 1

Individual and mean ( \pm S.E.M.) values of (A) fetal cortisol concentration and the activity of citrate synthase (CS) in (B) the biceps femoris (BF) and (C) superficial digital flexor (SDF) muscles of unoperated newborn lambs $(n=6)$ and fetal sheep delivered either unoperated at 104 days of gestational age ( dGA, $n=6$ ), at $129 \mathrm{dGA}$ after infusion with saline (S-I, $n=6$ ) or cortisol $(\mathrm{C}-\mathrm{I}, n=6)$ for 5 days before delivery at $129 \mathrm{dGA}$ or at $144 \mathrm{dGA}$ after adrenalectomy ( $A X, n=4$ ) or sham operation (Sham, for cortisol $n=6$, for $\mathrm{CS} n=5 \mathrm{BF}, n=6 \mathrm{SDF}$ ) at 114-119 dGA. Mean ( \pm S.E.M.) values for control to sham-operated fetuses at 144 dGA (Table 2). Cortisol infusion had no effect on protein content of either muscle, whereas AX reduced the protein content of the BF alone when expressed per gram wet weight but not per gram dry weight (Table 2). Cortisol infusion has no effect on the fetal blood gas status or concentrations of glucose and lactate during the infusion period before tissue collection (data not shown).

\section{Muscle mitochondrial content}

In control fetuses, CS activity increased towards term with a further increase after birth in both muscles (Fig. 1B and C), consistent with previous findings in the BF (Davies et al. 2020). Cortisol infusion had no effect on CS activity in the $\mathrm{BF}$ but significantly increased activity in the SDF relative to saline-infused control values (Fig. 1B and C). In contrast, CS activity was significantly less in AX than sham-operated fetuses near term in the BF but not in the SDF when comparing group means (Fig. 1B and C). However, a paired comparison between the AX fetus and its sham-operated twin showed CS activity was significantly less in the AX twin than its sibling for both the BF $(-0.090 \pm 0.006 \mu \mathrm{mol} /$ $\mathrm{min} / \mathrm{mg}$ protein, $n=4, P<0.01)$ and SDF $(-0.040 \pm 0.008$ $\mu \mathrm{mol} / \mathrm{min} / \mathrm{mg}$ protein, $n=4, P<0.05$, $t$-test for significance of single mean, both muscles).

When data from all the groups were combined irrespective of age or treatment, there were significant positive correlations between CS activity and the concentrations of both cortisol and $\mathrm{T}_{3}$ in each muscle (Table 3 ). As the cortisol and $\mathrm{T}_{3}$ concentrations were also correlated $(r=0.720, n=33, P<0.001)$, partial correlation analyses were used to determine the relative importance of the two hormones when the confounding effect of the other was taken into account. This showed that both hormones have significant influences on CS activity with plasma $\mathrm{T}_{3}$ as the more statistically significant factor in both muscles (Table 3).

\section{Muscle mitochondrial biogenesis and membrane dynamics}

Consistent with the changes in mitochondrial density, manipulating fetal cortisol concentrations had

animals (104 dGA, S-l, sham-operated and newborn animals) are shown with white columns while those for animals with cortisol concentrations that were manipulated experimentally (C-I and $A X)$ are shown with grey columns. Control columns with different letters as superscripts are significantly different from each other (one-way ANOVA, $P<0.05$ ). An asterisk indicates a significant difference from the respective control group ( ${ }^{*} P<0.05,{ }^{*} P<0.01, t$-test or Mann-Whitney Rank sum test). 
Table 2 Hormone concentrations, morphometry and biochemical composition. Mean ( \pm S.E.M.) values of T3 and T4 concentrations, morphometric measurements and muscle biochemical composition of the biceps femoris (BF) and superficial digital flexor (SDF) muscles of sheep fetuses delivered either at 129 days of gestational age (dGA) after a 5-day infusion of cortisol $(n=6)$ or saline $(n=6)$ or at 144 dGA after adrenalectomy $(n=4, \mathrm{AX})$ or sham operation $($ Sham, $n=6)$ at $114-119$ dGA.

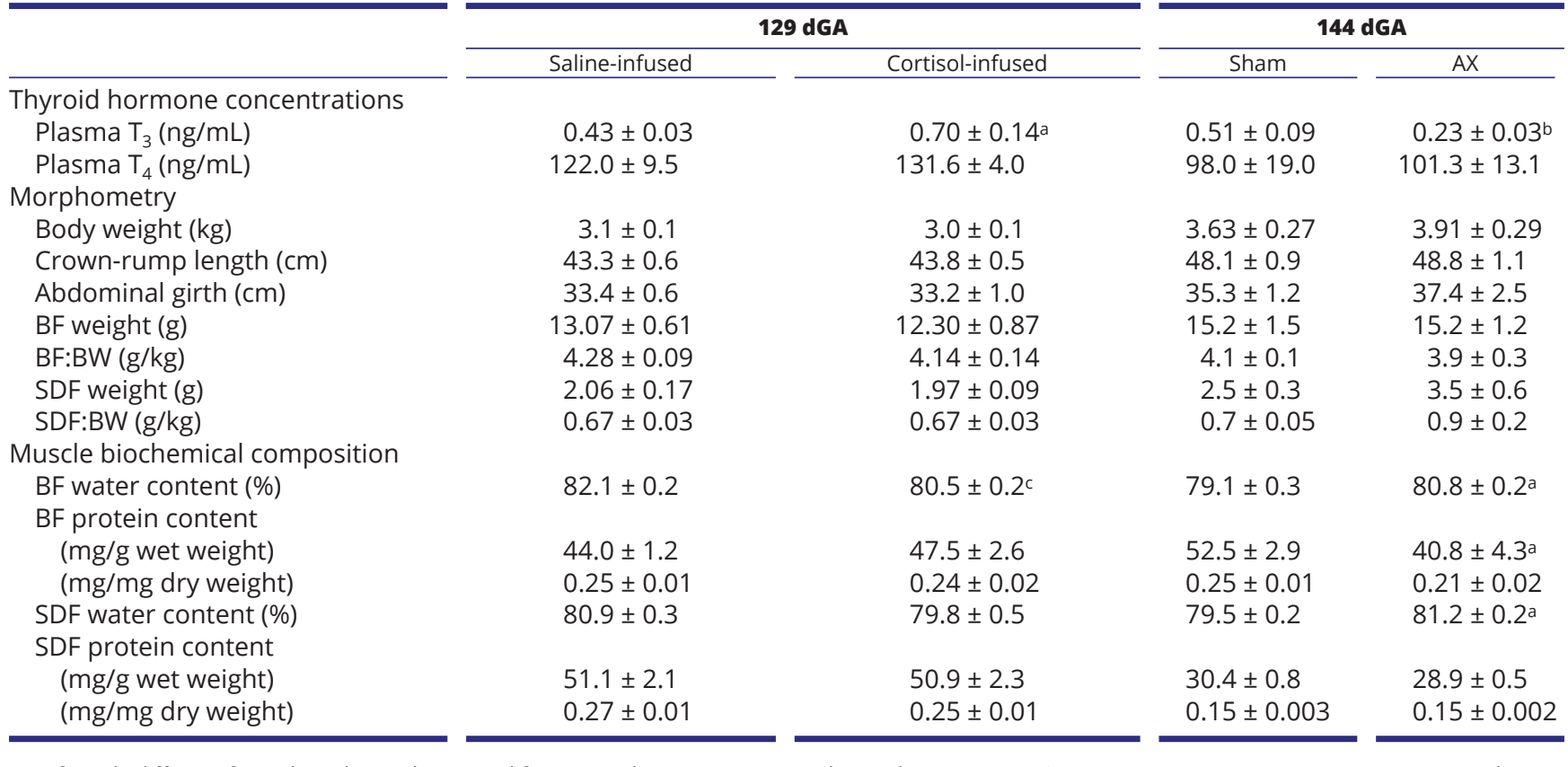

Significantly different from the value in the control fetuses at the same gestational age where $\mathrm{a} P<0.05 ; \mathrm{b} P=0.057$ ( $t$-test or non-parametric Mann-Whitney test as appropriate); $c P<0.01$.

muscle-specific effects on gene expression of $P G C 1 \alpha$ and $M F N 2$. Expression of $P G C 1 \propto$ was significantly higher in the SDF of cortisol - than saline-infused fetuses, but not in the $\mathrm{BF}$, and was reduced significantly by AX in both muscles near term (Fig. 2A and B). Expression of MFN2 in the BF was unaffected by varying cortisol concentrations (Fig. 2C). In contrast in the SDF, MFN2 expression was upregulated by cortisol infusion and down-regulated by $\mathrm{AX}$ relative to their respective controls (Fig. 2D). In both muscles, varying cortisol concentrations had no significant effect on DRP1 expression (Fig. 2E and F).

\section{Muscle oxygen consumption}

The ADP-coupled rates of $\mathrm{O}_{2}$ consumption by the two muscles are shown in Fig. 3 for the three different respiratory protocols. In the BF, cortisol infusion had no effect on maximal OXPHOS or PC-supported oxidative capacity but significantly increased Py-supported $\mathrm{O}_{2}$ consumption relative to saline-infused values (Fig. 3A, B and C). In contrast, in the SDF, cortisol infusion significantly increased maximal OXPHOS and PC-supported oxidative capacity together with a tendency for higher rates of Py-supported respiration compared to saline-infused values ( $P=0.064$, Fig. 3D, E and F). In both muscles, AX had no significant effect on respiratory rates using any of the substrates, although there was a tendency for lower BF rates of Py-supported respiration after AX ( $P=0.093$, Fig. 3B).

When the respiratory data were combined for all fetuses irrespective of treatment or gestational age for each substrate separately, there were significant positive correlations between the BF rate of Py-linked respiration and the concentrations of both cortisol and $\mathrm{T}_{3}$, although partial correlation showed no significant correlations with either hormone alone (Table 3). There were no significant correlations between the $\mathrm{BF}$ respiratory rates with the other substrates and either hormone concentration (Table 3). In the SDF, cortisol concentrations were positively correlated with PC-linked respiration and maximal OXPHOS but not Py-linked respiration while $\mathrm{T}_{3}$ levels were positively correlated to all three respiratory rates (Table 3). Partial correlation of the SDF data showed no effect of either cortisol or $\mathrm{T}_{3}$ alone on PC-linked respiration but a statistically dominant effect of $\mathrm{T}_{3}$ on maximal OXPHOS (Table 3).

In the $\mathrm{BF}$, leak state respiration, a measure of $\mathrm{O}_{2}$ consumption for processes other than ATP production, was unaffected by manipulating fetal cortisol concentrations,

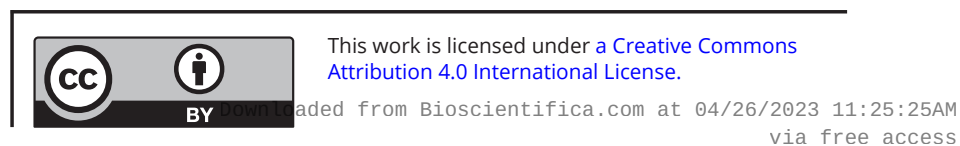


Table 3 Correlation and partial correlation analyses between hormone concentrations and citrate synthase activity and mitochondrial oxidative phosphorylation (OXPHOS) rates of the fetal biceps femoris (BF) and superficial digital flexor (SDF) muscles. For each muscle, data were combined from the cortisol infused and adrenalectomised and their respective control groups of fetuses.

\begin{tabular}{|c|c|c|}
\hline Muscle & Hormone & Citrate synthase \\
\hline \multicolumn{3}{|c|}{ Correlations } \\
\hline BF & $\log _{10}$ cortisol & $\begin{array}{l}r=0.735 \\
P<0.01 \\
n=33 \\
r=0.803 \\
P<0.001 \\
n=33\end{array}$ \\
\hline SDF & $\begin{array}{l}\log _{10} \text { cortisol } \\
\log _{10} T_{3}\end{array}$ & $\begin{array}{l}r=\mathbf{0 . 7 0 1} \\
P<0.001 \\
n=32 \\
r=0.801 \\
P<0.001 \\
n=32\end{array}$ \\
\hline \multicolumn{3}{|c|}{ Partial correlations } \\
\hline \multirow[t]{2}{*}{$\mathrm{BF}$} & $\log _{10}$ cortisol & $\begin{array}{l}r=\mathbf{0 . 3 8 7} \\
P<0.05\end{array}$ \\
\hline & $\log _{10} T_{3}$ & $\begin{array}{l}r=\mathbf{0 . 5 8 2} \\
P<0.01 \\
n=33\end{array}$ \\
\hline \multirow[t]{2}{*}{ SDF } & $\log _{10}$ cortisol & $\begin{array}{l}r=\mathbf{0 . 4 2 4} \\
P<0.05\end{array}$ \\
\hline & $\log _{10} T_{3}$ & $\begin{array}{l}r=\mathbf{0 . 5 0 6} \\
P<0.01 \\
n=32\end{array}$ \\
\hline
\end{tabular}

Py-linked OXPHOS

$r=\mathbf{0 . 4 8 2}$

$P<0.05$

$n=22$

$r=\mathbf{0 . 4 6 0}$

$P<0.05$

$n=22$

$r=0.203$

$P>0.05$

$n=21$

$r=0.428$

$P<0.05$

$n=21$

PC-linked OXPHOS

Maximal OXPHOS

$r=0.350$

$P>0.05$

$r=0.310$

$P>0.05$

$n=21$

Not required

Not required

$P>0.05$

$r=-0.050$

$P>0.05$

$n=19$

$r=0.272$

$P>0.05$

$n=19$

$r=0.507$

$P<0.05$

$n=19$

$r=\mathbf{0 . 4 4 6}$

$P=0.050$

$n=19$

$R=0.263$

$P>0.05$

$n=22$

$R=0.304$

$P>0.05$

$n=22$

$r=\mathbf{0 . 4 2 1}$

$P<0.05$

$n=21$

$r=0.566$

$P<0.01$

$n=21$

Not required Not required

Not required

Not required

$r=0.279$

$P>0.05$

$n=19$

$r=0.215$

$P>0.05$

$r=0.478$

$P<0.01$

$n=21$

Significant correlations and partial correlations are shown in bold $(P \leq 0.05)$.

irrespective of substrate (data not shown). In the SDF, leak state respiration with $\mathrm{PC}$ was significantly higher in cortisol - $\left(1.30 \pm 0.21 \mathrm{nmolO}_{2} / \mathrm{min} / \mathrm{mg}\right.$ dry weight, $\left.n=5\right)$ than saline-infused fetuses $\left(0.69 \pm 0.17 \mathrm{nmolO}_{2} / \mathrm{min} / \mathrm{mg}\right.$ dry weight, $n=6, P<0.05$ ) but not with the other substrates (data not shown). Adrenalectomy had no significant effect on the SDF leak state respiration using any of the substrates (data not shown). There were no significant correlations between any of leak state respiratory rates and the concentrations of either hormone $(P>0.05$, all cases).

\section{ETS and other mitochondrial OXPHOS regulatory proteins}

In the BF, cortisol infusion significantly increased protein abundance of ETS complex I but had no effect on any of the other complexes or ATP synthase (Fig. 4A). Complexes I-IV and ATP synthase were also unaffected by cortisol infusion in the SDF (Fig. 4B). In contrast, AX had no significant effect on protein abundance of complexes I-IV or ATP synthase in the BF but reduced complex IV abundance alone in the SDF relative to sham-operated values (Fig. 4C and D). Gene expression for the uncoupling proteins, UCP2 and
UCP3, was unaffected by treatment in both muscles (Fig. $5 \mathrm{~A}, \mathrm{~B}, \mathrm{C}$ and $\mathrm{D}$ ). In the SDF, cortisol infusion significantly increased both gene expression and protein abundance of ANT1 whereas, in the BF, it had no significant effect on either ANT1 measure, although there was a tendency for higher protein abundance relative to saline-infused values $(P=0.095$, respectively, Fig. 5E, F, G and H). Adrenalectomy reduced gene and protein ANT1 levels significantly in both muscles (Fig. 5E, F, G and H).

\section{Muscle expression of myosin heavy chain $(M H C)$ isoforms}

The effects of manipulating the fetal cortisol concentration on fibre composition of the two muscles was assessed by quantifying $M H C$ isoform expression for the type 1 slowtwitch, oxidative fibres with abundant mitochondria (MHCI) and the type II fast-twitch fibres that have fewer mitochondria and are either oxidative/glycolytic, MHCIIa, or predominantly glycolytic, MHCIIx (Yates et al. 2016). In both muscles, cortisol infusion had no significant effect on expression of the MHCI or MHCIIa isoforms (Fig. $6 \mathrm{~A}, \mathrm{~B}, \mathrm{D}$ and $\mathrm{E})$. In contrast, MHCIIx expression in the BF 
A

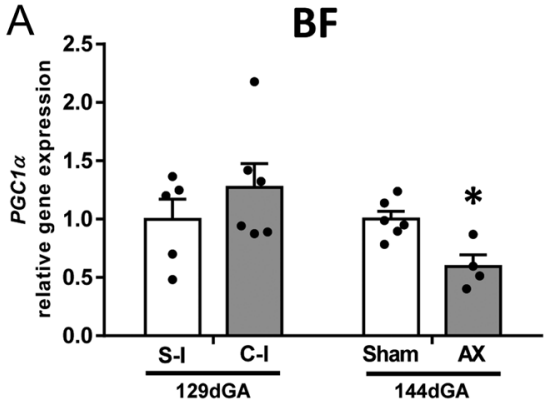

C
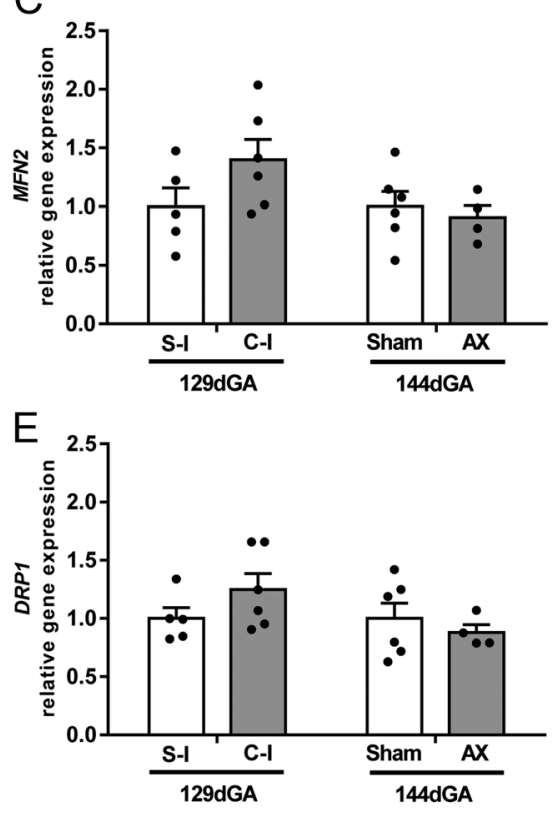

B



D

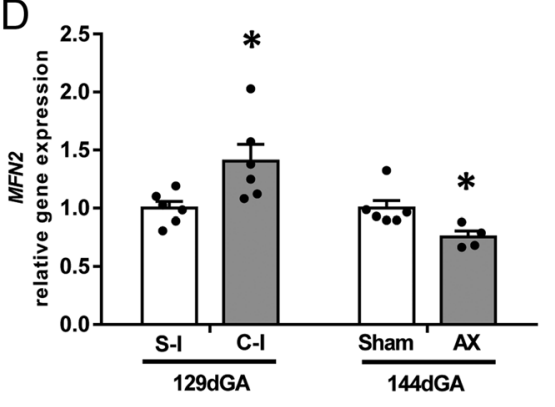

$\mathrm{F}$

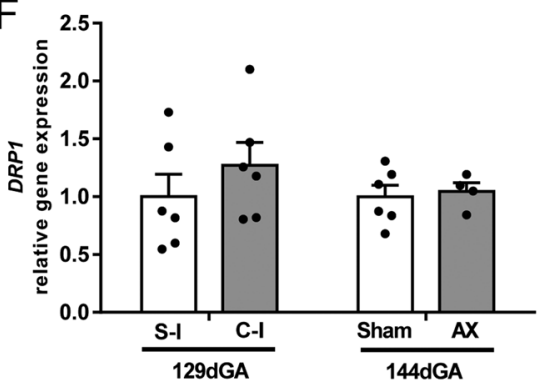

Figure 2

Mean ( \pm S.E.M.) relative gene expression of $P G C 1 \alpha$ (panels A and B), MFN2 (panels C and D) and DRP1 (panels $\mathrm{E}$ andF) in the biceps femoris (BF, panels $\mathrm{A}$, $\mathrm{C}$ and $\mathrm{E}$ ) and superficial digital flexor (SDF, panels B, $D$ and $F$ ) muscles of fetal sheep either at 129 days of gestational age (dGA) after 5 days of infusion of saline (S-I, $n=5 \mathrm{BF}, n=6 \mathrm{SDF}$ ) or cortisol (C-I, $n=6$, both muscles) or at 144 dGA after adrenalectomy (AX, $n=4$, both muscles) or sham operation (Sham, $n=6$, both muscles) at 114-119 dGA. An asterisk indicates a significant difference from the respective control group ( ${ }^{*} P<0.05, t$-test or Mann-Whitney Rank sum test). was increased by cortisol infusion and decreased by $\mathrm{AX}$ relative to their respective controls (Fig. 6C). No change in MHCIIx expression was seen in the SDF with either treatment (Fig. 6F).

\section{Discussion}

The results show that variations in fetal cortisol concentrations within the physiological range affect mitochondrial OXPHOS capacity in ovine skeletal muscles near term. The effects were muscle-specific and were associated with changes in mitochondrial content, biogenesis markers and abundance of specific ETS complexes and ANT1. They were accompanied by substrate-specific alterations in respiratory function. In addition, there were muscle-specific changes in $\mathrm{MHC}$ isoform expression in response to altering fetal cortisol concentrations. The cortisol-dependent changes in mitochondrial function are summarised in Table 4 for the two muscles. Collectively, they indicate that the normal prepartum rise in fetal cortisol concentrations has a key role in maturing mitochondrial capacity in preparation for the increased energy demands of skeletal muscle postnatally.

In the current study, mitochondrial content was reduced in both muscles when the normal prepartum cortisol surge was prevented by fetal AX. In rats, suppressing fetal corticosterone concentrations close to term by maternal AX and metopirone treatment reduces mitochondrial content of the fetal kidney but not the liver or heart (Prieur et al. 1998). Short-term maternal administration of a potent synthetic glucocorticoid, dexamethasone, near term, restored the normal renal mitochondrial density in these glucocorticoid-deficient rat pups and also increased the volume density of mitochondria in type II pneumocytes of normal fetal rabbits (Snyder et al. 1992, Prieur et al. 1998). In the current study, raising cortisol level to prepartum values by cortisol infusion before the normal surge increased mitochondrial content, specifically in the SDF. In a recent study, longerterm treatment of pregnant ewes with cortisol for the last 25 days of pregnancy reduced mitochondrial DNA 

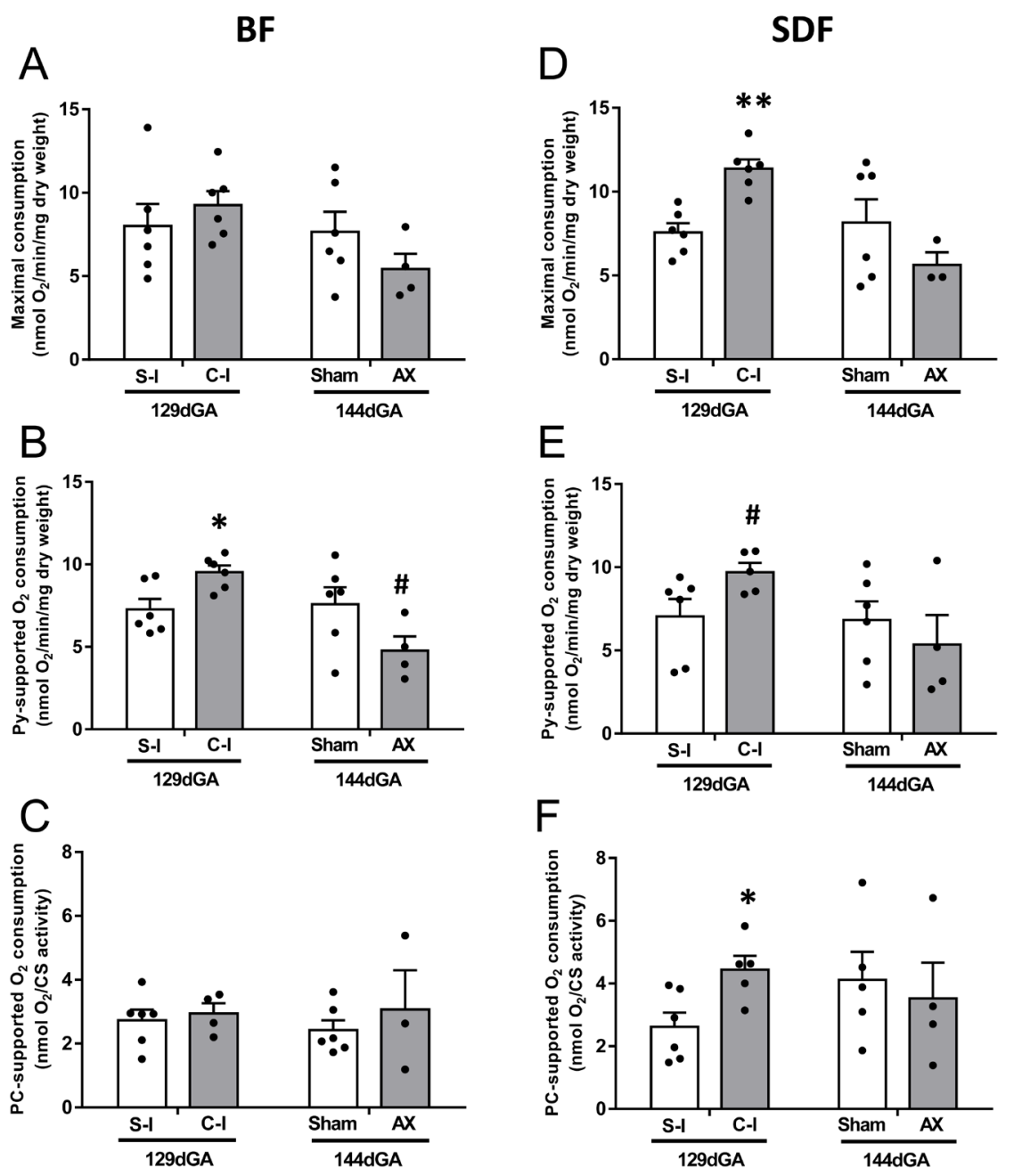

\begin{abstract}
Figure 3
Mean ( \pm S.E.M.) maximal (panels $A$ and D), pyruvate supported (Py, panels $B$ and $E$ ) and palmitoylcarnitine supported ( $P C$, panels $C$ and $F$ ) rates of oxygen consumption by the biceps femoris (BF, panels $A, B$ and $C$ ) and superficial digital flexor (SDF, panels D, E and F) muscles of fetal sheep either at 129 days of gestational age (dGA) after 5 days of infusion of saline (S-I, $n=6$, both muscles) or cortisol (C-I, $n=4-6 \mathrm{BF}, n=5-6 \mathrm{SDF})$ or at $144 \mathrm{dGA}$ after adrenalectomy ( $\mathrm{AX}, n=3-4$, both muscles) or sham operation (Sham, $n=6 \mathrm{BF}$, $n=5-6$ SDF) at 114-119 dGA. An asterisk indicates a significant difference from the respective control group $(* P<0.05, * * P<0.01, t$-test or Mann-Whitney Rank sum test). A hash tag indicates a trend towards a significant difference from the respective control group ( $\# P<0.10, t$-test or Mann-Whitney Rank sum test).
\end{abstract}

content of the fetal BF and heart at term (Joseph et al. 2020). Similarly, maternal corticosterone treatment of rats at mid-pregnancy decreased placental mitochondrial density (Bartho et al. 2019). In the current study, muscle mitochondrial content increased between 104 and 129 dGA in the absence of any cortisol increment. This coincides with a major period of muscle fibre differentiation and suggests that factors other than circulating cortisol, such as growth factors and receptor abundances, may be involved in mitochondrial development earlier in gestation (Florini et al. 1991, Walker \& Luff 1995, Bloise et al. 2018). Collectively, these findings suggest that glucocorticoids are required for normal mitochondrial biogenesis near term in specific fetal tissues but that, earlier in gestation, their actions may depend not only on the tissue and its stage of development but also on the duration, timing, route and type of glucocorticoid exposure.

The changes in muscle mitochondrial density seen in response to varying fetal cortisol levels in the current study tracked closely with the expression of the key regulator of mitochondrial biogenesis, $P G C 1 \alpha$ (Table 4). Alterations in $P G C 1 \alpha$ expression were more pronounced in the SDF than BF and were accompanied by parallel changes in SDF expression of MFN2, a gene essential for normal membrane dynamics and OXPHOS function that is regulated by $P G C 1 \alpha$ (Liang \& Ward 2006). Previous studies on rodents have shown that $P G C 1 \alpha$ expression is glucocorticoid sensitive and increases towards term in fetal heart and adipose tissue (Rog-Zielinska et al. 2015, Chen et al. 2020). Deletion of PGC1 $\alpha$ expression in fetal mice also impairs mitochondrial OXPHOS function and the metabolic response to glucocorticoids in developing cardiomyocytes (Rog-Zielinska etal. 2015). Conversely, overexpression of $P G C 1 \alpha$ promotes mitochondrial biogenesis and $\mathrm{O}_{2}$ consumption in neonatal cardiomyocytes in vitro (Lehman et al. 2000). However, no prepartum upregulation of $P G C 1 \alpha$ expression was seen in fetal ovine BF, despite a concomitant increase in mitochondrial density towards term (Davies et al. 2020). 
A

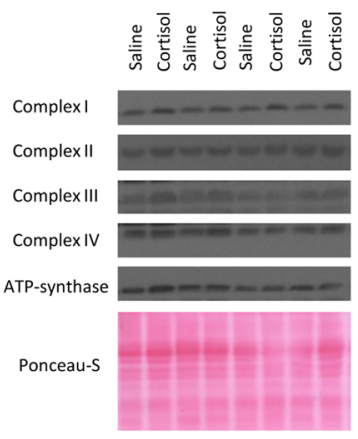

C

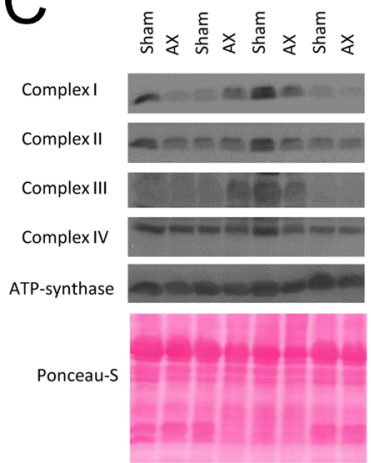

BF

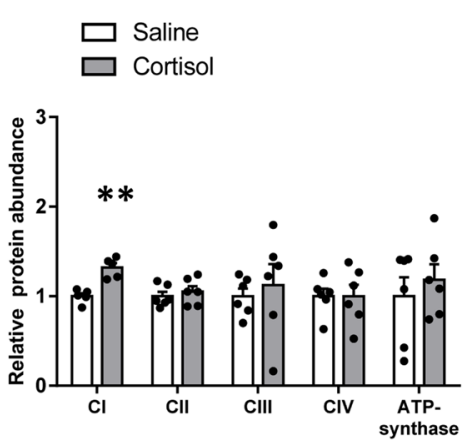

B

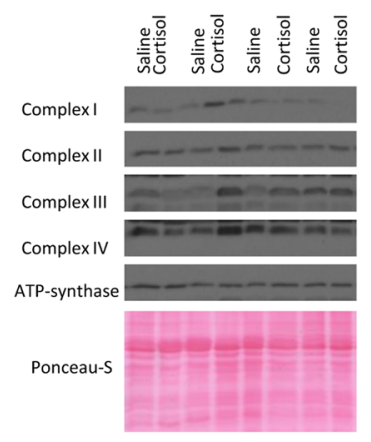

D

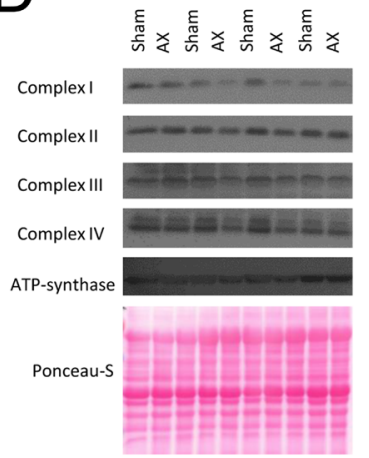

SDF

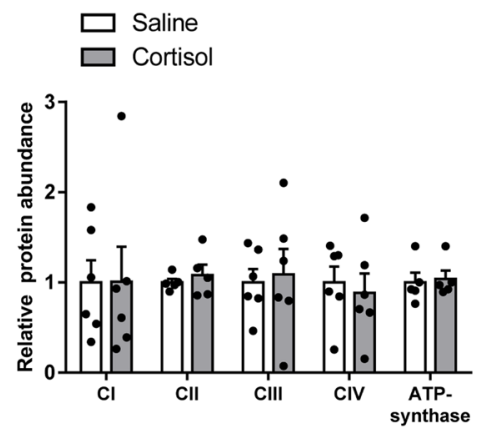

\section{Figure 4}

Mean ( \pm S.E.M.) relative protein abundance of the electron transfer system complexes (CI-IV) and ATP synthase (CV) in the biceps femoris (BF, panels A and C) and superficial digital flexor (SDF, panels B and D) muscles in fetal sheep either at 129 days of gestational age (dGA) after 5 days of infusion of saline (white columns, $n=5 \mathrm{BF}, n=6 \mathrm{SDF}$ ) or cortisol (grey columns, $n=6$, both muscles) in panels A and B or at 144 dGA after adrenalectomy (AX, grey columns, $n=4$, both muscles) or sham operation (white columns, $n=6$, both muscles) at $114-119$ dGA in panels $C$ and $\mathrm{D}$. An asterisk indicates a significant difference from the respective control group ( $* P<0.05, * \star p<0.01, t$-test or Mann-Whitney Rank sum test). A full colour version of this figure is available at https://doi.org/10.1530/JOE-21-0171.

Previous rodent studies have shown increases in mitochondrial respiration and/or expression of complex IV and ATP synthase in heart, liver and brain of fetal and neonatal pups in response to dexamethasone treatment (Prieur et al. 1998, Lehman et al. 2000, Nakai et al. 2002, Rog-Zielinska et al. 2015). In the present study, raising cortisol levels within the physiological range increased mitochondrial OXPHOS capacity in both fetal skeletal muscles but in a substrate-specific manner. In the BF, cortisol stimulated respiration with pyruvate by $30 \%$ but not with the other substrates. This occurred without any significant change in mitochondrial content but was accompanied by a similar percentage increase in complex I abundance, consistent with pyruvate being an electron donor to this complex via NADH (Kuznetsov et al. 2008). There was, however, no accompanying increase in maximal OXPHOS capacity, supported by saturating concentrations of substrates for complex I and complex II, which may be due to limitations at the Q-junction for electron entry to complex III, which did not increase in abundance. Cortisol-induced upregulation of Py-linked respiration in the $\mathrm{BF}$ was also accompanied by greater MCHIIx expression consistent with the increased $\mathrm{BF}$ abundance of MCHIIx glycolytic fibres seen previously towards term (Davies et al. 2020). Collectively, the current findings in the BF may suggest that the mitochondrial content of its oxidative fibres increases in response to cortisol infusion. In contrast, in the SDF, cortisol infusion resulted in significant rises in PC-linked and maximal OXPHOS capacity together with a tendency for higher rates of Py-supported respiration (Table 4). These respiratory changes occurred without alteration in $M H C$ expression but concomitantly with increased mitochondrial biogenesis and content. However, preventing the prepartum fetal cortisol surge by AX had no significant effect on mitochondrial respiration in either muscle irrespective of substrate, despite decreased expression of MHCIIX in the BF and lower mitochondrial density and $P G C 1 \alpha$ expression in both muscles. Thus, cortisol appears to act on mitochondrial OXPHOS

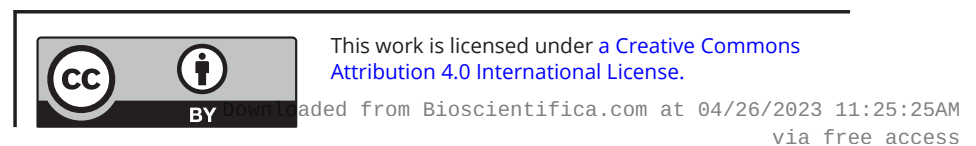


A

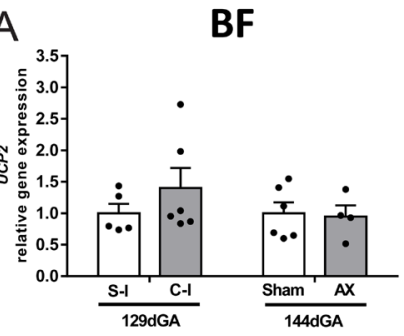

C

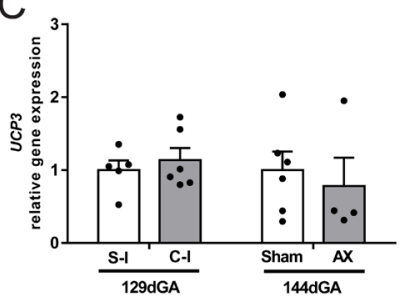

E

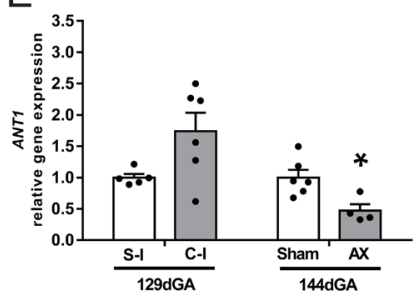

G
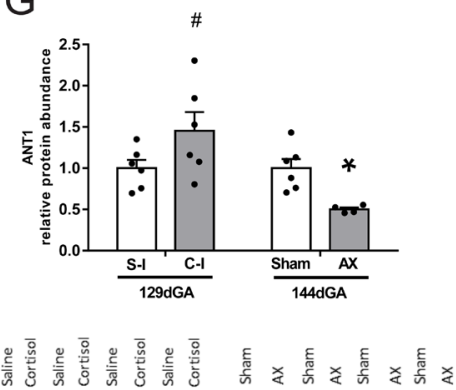

ANT1


B

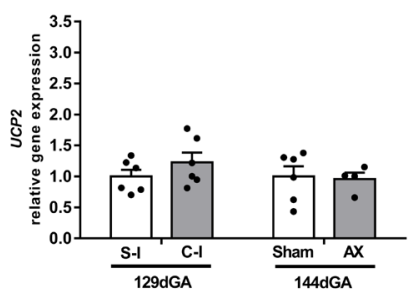

D

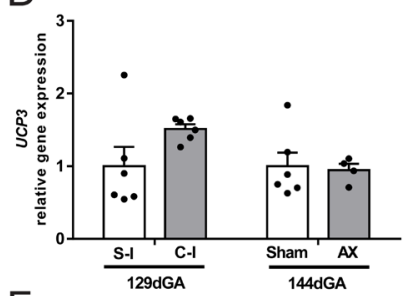

$F$

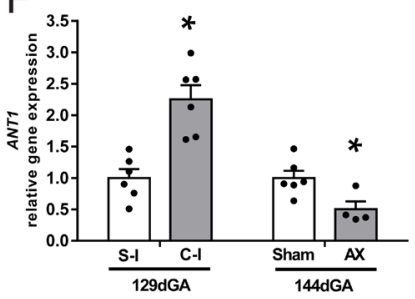

$\mathrm{H}$
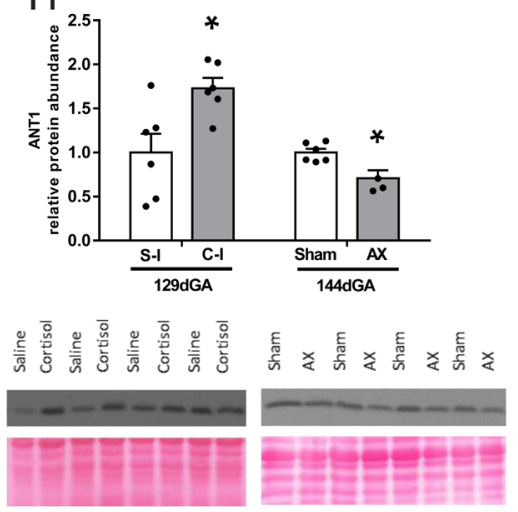

\section{Figure 5}

Mean ( \pm S.E.M.) relative gene expression of UCP2 (panels A and B), UCP3 (panels C and D), and ANT1 (panels $E$ and F) and of ANT1 protein abundance (panels $\mathrm{G}$ and $\mathrm{H}$ ) in the biceps femoris ( $B F$, panels $A, C, E$ and $G$ ) and superficial digital flexor (SDF, panels $B, D, F$ and $H$ ) muscles of fetal sheep either at 129 days of gestational age (dGA) after 5 days of infusion of saline (S-I, $n=5 B F, n=6 S D F$ ) or cortisol (C-I, $n=6$, both muscles) or at 144 dGA after adrenalectomy ( $\mathrm{AX}, n=4$, both muscles) or sham operation (Sham, $n=6$, both muscles) at 114-119 dGA. An asterisk indicates a significant difference from the respective control group $\left({ }^{*} P<0.05,{ }^{*} P<0.01, t\right.$-test or Mann-Whitney Rank sum test). A hash tag indicates a trend towards a significant different from the respective control group $(\# P<0.10, t$-test or Mann-Whitney Rank sum test). A full colour version of this figure is available at https://doi.org/10.1530/ JOE-21-0171. in utero through different muscle-specific mechanisms, which may also depend on gestational age.

The discrepancy between the effects of cortisol on respiratory rates at 129 and 144 dGA may reflect, in part, differences in the duration of cortisol exposure between the single infused and twin sham-operated fetuses as activation of the fetal hypothalamic-pituitary-adrenal axis, and the rise in fetal cortisol concentrations occurs more rapidly and closer to term in twin than single sheep fetuses (Edwards \& McMillen 2002). Since cortisol activates the deiodinases converting $\mathrm{T}_{4}$ to $\mathrm{T}_{3}$ (Forhead et al. 2006), the current findings that fetal $\mathrm{T}_{3}$ concentrations were increased by 5 days of cortisol infusion but did not differ significantly between sham-operated and AX fetuses later in gestation would be consistent with a shorter period of cortisol exposure in the sham-operated twin fetuses. Thyroid hormones are known to affect mitochondrial function in adult tissues and their fetal deficiency has recently been shown to impair mitochondrial OXPHOS capacity of the fetal ovine BF and brain (Lombardi et al. 2015, Bloise et al. 2018, Davies et al. 2020, 2021). Indeed, the current findings suggest that both cortisol and $\mathrm{T}_{3}$ are important factors in regulating mitochondrial content and OXPHOS capacity of skeletal muscle during late gestation. The prepartum maturational effects of cortisol on mitochondrial function in skeletal muscle may, therefore, be mediated, in part, by $\mathrm{T}_{3}$ as occurs with other metabolic processes which are essential for neonatal survival (Forhead \& Fowden 2014).

The current findings in AX fetuses indicate that the prepartum cortisol increment increases mitochondrial 
A

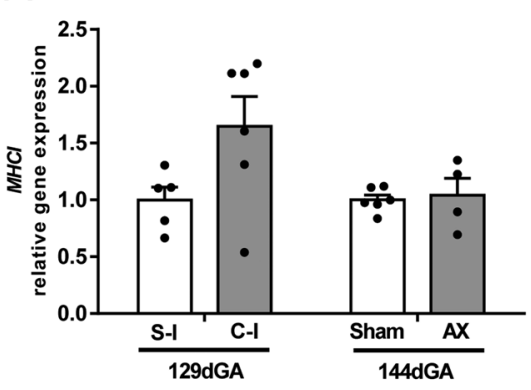

B

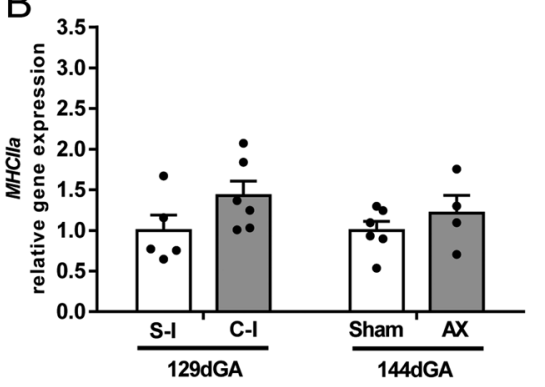

C

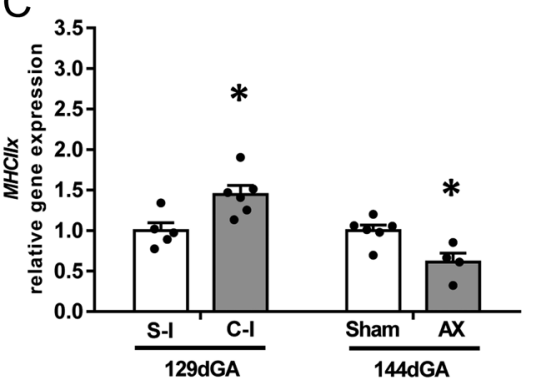

D

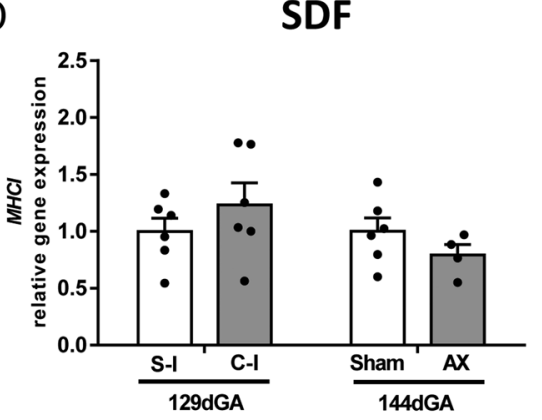

E

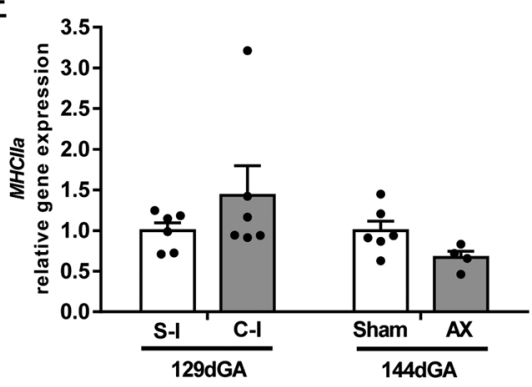

$\mathrm{F}$

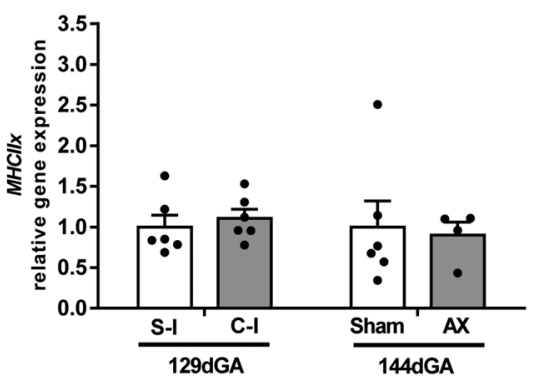

\section{Figure 6}

Mean ( \pm S.E.M.) relative gene expression of $\mathrm{MHCl}$ (panels A and D), MHClla (panels D and E), and MCHIIx (panels $C$ and $F$ ) in the biceps femoris (BF, panels $A, B, C$ ) and (C) superficial digital flexor (SDF, panels D, E, F) muscles of fetal sheep either at 129 days of gestational age ( dGA) after 5 days of infusion of saline (S-I, $n=5 B F, n=6 S D F$ ) or cortisol (C-I, $n=6$, both muscles) or at $144 \mathrm{dGA}$ after adrenalectomy ( $A X, n=4$, both muscles) or sham operation (Sham, $n=6$, both muscles) at 114-119 dGA. An asterisk indicates a significant difference from the respective control group ( $P<0.05$, $t$-test or Mann-Whitney Rank sum test). content in both muscles. However, earlier in gestation when muscle fibres were still differentiating, the effects of cortisol are more complex and appear to be muscle and possibly fibre-type specific. In the SDF, cortisol infusion increased mitochondrial biogenesis, content and maximal OXPHOS, but with no apparent increase in ETS complex abundance. In the BF, cortisol infusion had no effect on mitochondrial content or maximal OXPHOS, but specifically increased complex I capacity and altered the relative contribution of the different muscle fibres to the mitochondrial pool. In both muscles, there were no changes in ATP synthase or UCPs with experimental manipulation of the fetal cortisol concentration that would explain the changes in OXPHOS functional capacity, although UCP expression may not reflect the activity. This contrasts with the known effects of cortisol in upregulating UCP abundance in fetal ovine adipose tissue near term (Mostyn et al. 2004, Gnanalingham et al. 2008). In general, ANT1 levels were increased by cortisol infusion and reduced by AX in both muscles in the current study. As well as functioning as a mitochondrial ADP-ATP exchanger, ANT1 can induce mild mitochondrial uncoupling in adult tissues, particularly in response to fatty acids (Kimura \& Rasmussen 1977, Brand et al. 2005, Sparks et al. 2016). This is consistent with the current finding of greater ANT1 abundance concurrently with increased SDF rates of both PC-linked leak and OXPHOS respiration in cortisol-infused fetuses. In adult rat liver, dexamethasone has been shown to increase ANT1 content and simultaneously enhance both mitochondrial uncoupling and OXPHOS capacity (Arvier et al. 2007). The prepartum rise in cortisol may, therefore, act to stimulate mitochondrial biogenesis and, thus, the capacity for neonatal ATP production while minimising the potential for oxidative stress, in part through dissipating the proton gradient. Other factors may then activate the increase in mitochondrial OXPHOS after birth when the ATP demand rises with the new metabolic activities (Fowden \& Forhead 2015).

In summary, the current findings show that cortisol is an important regulator of mitochondrial OXPHOS https://joe.bioscientifica.com https://doi.org/10.1530/JOE-21-0171 (c) 2021 The authors Published by Bioscientifica Ltd. Printed in Great Britain
This work is licensed under a Creative Commons Attribution 4.0 International License. 
Table 4 Summary of the changes induced in the biceps femoris and superficial digital flexor muscles either by pre-term cortisol infusion for 5 days to mimic the normal prepartum increase in cortisol concentration or by adrenalectomy (AX) to prevent this increment near term relative to their respective control groups.

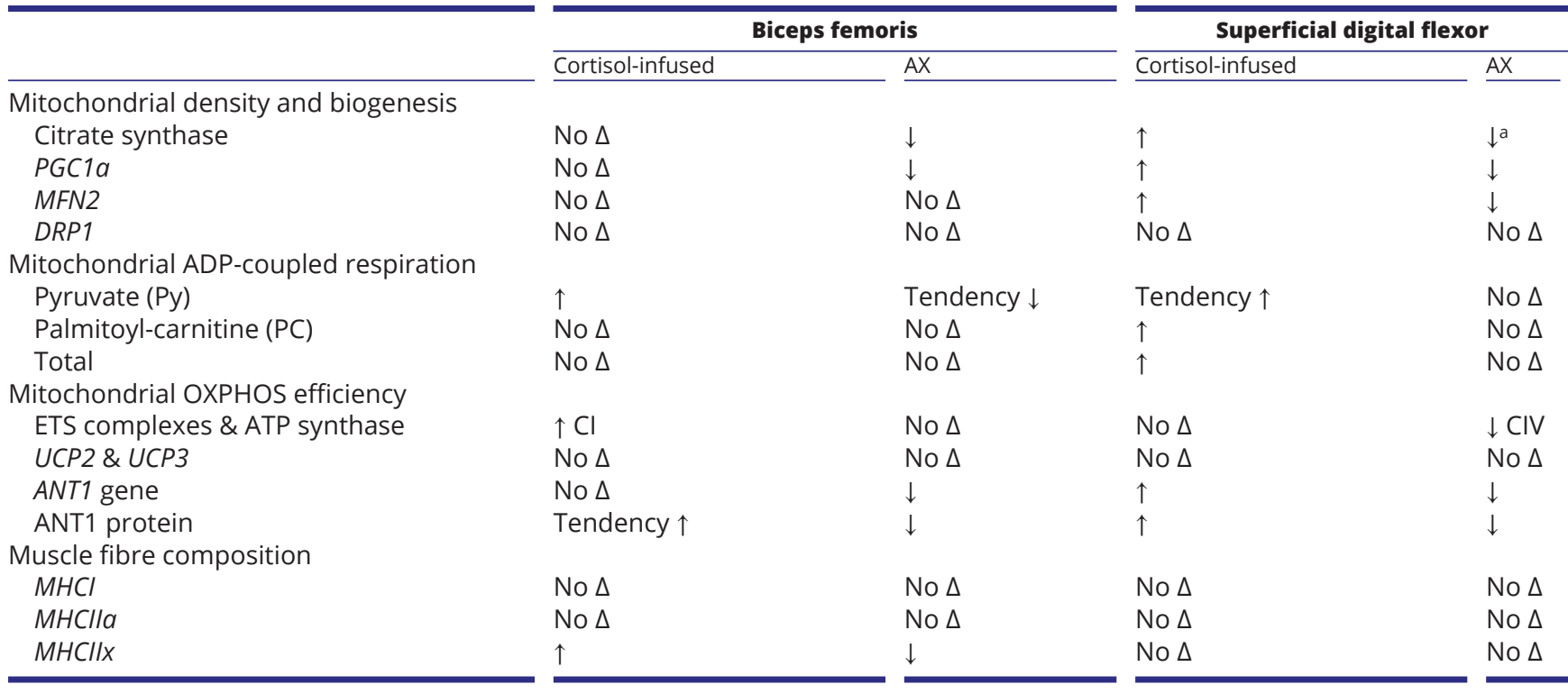

$\downarrow$ Significant decrease $(P<0.05)$ or tendency for decrease $(P<0.10)$; aSignificant decrease by paired t-test to its sham-operated twin $(P<0.05) ; \uparrow$ Significant increase $(P<0.05)$ or tendency for increase $(P<0.10)$.

$\mathrm{Cl}$, ETS complex I; CIV, ETS complex IV; No $\Delta$, no significant change.

capacity in the ovine skeletal muscle duringlate gestation. Its effects were muscle-specific and involved changes in mitochondrial biogenesis and respiratory function. Indeed, these prenatal cortisol-induced adaptations may explain, in part, the adult mitochondrial dysfunction observed after adverse conditions during pregnancy that raises fetal glucocorticoid concentrations (Reynolds 2013, Khamoui et al. 2018, Chen et al. 2020, Gyllenhammer et al. 2020). While glucocorticoids are known to affect adult mitochondrial function through both the nuclear and mitochondrial genomes (Lapp et al. 2019), further studies are needed to determine the specific molecular mechanisms by which cortisol induces mitochondrial maturation in skeletal muscle fibres. Greater knowledge of these developmental processes will be beneficial for the metabolic health of infants under- or overexposed to glucocorticoids prenatally due to stress, prematurity or maternal treatment with synthetic glucocorticoids for threatened pre-term delivery or other clinical conditions.

\section{Declaration of interest}

The authors declare that there is no conflict of interest that could be perceived as prejudicing the impartiality of the research reported.

\section{Funding}

The work was supported by a grant to A L F and A J M by the Biotechnology and Biological Sciences Research Council (BB/P019048/1).

\section{Author contribution statement}

The study was designed by $K L D, O R V, A J M$ and $A L F$. The in vivo experimental work on the animals was carried out by $K L D, E J C, D$ J,$A$ $J F$ and $A L F$. The in vitro tissue analyses were carried out by $K L D, D J S, E$ J C and A J M. The manuscript was written by K L D and A L F. All the other authors commented on the text.

\section{Acknowledgements}

The authors thank the staff of the University Biomedical Services for their care of the animals and the technical staff of the Department of Physiology, Development and Neuroscience who assisted with this study.

\section{References}

Arvier M, Langoutte L, Johnson G, Dumas JF, Sion B, Grizard G, Malthiery Y, Simard G \& Ritz P 2007 Adenine nucleotide translocator promotes oxidative phosphorylation and mild uncoupling in miotchondria after dexamethasone treatment. American Journal of Physiology: Endocrinology and Metabolism 293 E1320-E1324. (https:// doi.org/10.1152/ajpendo.00138.2007)

Barnes RJ, Co mline RS \& Silver M 1978 Effect of cortisol on liver glycogen concentration in hypophysectomised, adrenalectomised and normal https://joe.bioscientifica.com https://doi.org/10.1530/JOE-21-0171 (c) 2021 The authors Published by Bioscientifica Ltd. Printed in Great Britain

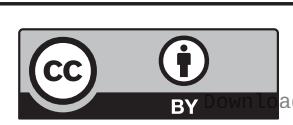

This work is licensed under a Creative Commons Attribution 4.0 International License. 
fetal lambs during late or prolonged gestation. Journal of Physiology 275 567-579. (https://doi.org/10.1113/jphysiol.1978.sp012209)

Bartho LA, Holland OJ, Moritz KM, Perkins AV \& Cuffe JSM 2019 Maternal corticosterone in the mouse alters oxidative stress, antioxidant function and mitochondrial content in placentas of female fetuses. Journal of Physiology 597 3053-3067. (https://doi.org/10.1113/JP277815)

Bartho LA, Fisher JJ, Cuffe JSM \& Perkins AV 2020 Mitochondrial transformations in the aging human placenta. American Journal of Physiology: Endocrinology and Metabolism 319 E981-E994. (https://doi. org/10.1152/ajpendo.00354.2020)

Biewener AA 1998 Muscle function in vivo: a comparison of muscles used for elastic energy savings versus muscles used to generate mechanical power. American Zoologist 38 703-717. (https://doi.org/10.1093/ $\mathrm{icb} / 38.4 .703)$

Bloise FF, Cordeiro A \& Ortiga-Caevalho TM 2018 Role of thyroid hormones in skeletal muscle. Journal of Endocrinology 236 R57-R68. (https://doi. org/10.1530/JOE-16-0611)

Brand MD, Pakay JL, Ocloo A, Kokoszka J, Wallace DC, Brookes PS \& Cornwall EJ 2005 The basal proton conductance of mitochondria depends on adenine nucleotide translocase content. Biochemical Journal 392 353-362. (https://doi.org/10.1042/BJ20050890)

Byrne K, Vuocolo T, Goudro C, White JD, Cockett NE, Hadfield T, Bidwell CA, Waddell JN \& Tellam RL 2010 A gene network switch enhances oxidative capacity of ovine skeletal muscles during late fetal development. BMC Genomics 11 378. (https://doi.org/10.1186/14712164-11-378)

Casuro RA \& Huertas JR 2020 The emerging role of skeletal muscle mitochondrial dynamics in exercise and ageing. Ageing Research Reviews 58 101025. (https://doi.org/10.1016/j.arr.2020.101025)

Chandhol G, Lazaron M \& Neumann B 2018 Structure, function and regulation of mitofusin-2 in health and disease. Biological Reviews of the Cambridge Philosophical Society 93 933-949. (https://doi.org/10.1111/ brv.12378)

Chen YT, Hu Y, Yang QY, Son JS, Liu XD, de Avila JM, Zhu MJ \& Du M 2020 Excessive glucocorticoids during pregnancy impair fetal brown fat development and predispose offspring to metabolic dysfunctions. Diabetes 69 1662-1674. (https://doi.org/10.2337/db20-0009)

Davies KL 2018 Developmental regulation of mitochondrial function in ovine fetal skeletal muscle. PhD thesis, University of Cambridge. (available at: www.repository.cam.ac.uk)

Davies KL, Camm EJ, Atkinson EV, Lopez T, Forhead AJ, Murray AJ \& Fowden AL 2020 Developmental and thyroid hormone dependence of skeletal muscle mitochondrial function towards birth. Journal of Physiology 598 2453-2468. (https://doi.org/10.1113/JP279194)

Davies KL, Smith DJ, El-Bacha T, Stewart ME, Easwaran A, Wooding PFP, Forhead AJ, Murray AJ, Fowden AL \& Camm EJ 2021 Development of cerebral mitochondrial respiratory function is impaired by thyroid hormone deficiency before birth in a region-specific manner. FASEB Journal 35 e21591. (https://doi.org/10.1096/fj.202100075R)

Djouadi F, Bastin J, Gilbert T, Rotig A, Rustin P \& Merlet-Benichou C 1994 Mitochondrial biogenesis and development of respiratory chain enzymes in kidney cells: role of glucocorticoids. American Journal of Physiology 267 C245-C254. (https://doi.org/10.1152/ ajpcell.1994.267.1.C245)

Du J, Wang Y, Hunter R, Wei Y, Blumenthal R, Falke C, Khairova R, Zhou R, Yuan P, Machado-Vieira R, et al. 2009 Dynamic regulation of mitochondrial function by glucocorticoids. PNAS 106 3543-3548. (https://doi.org/10.1073/pnas.0812671106)

Edwards LJ \& McMillen IC 2002 Impact of maternal undernutrition during the periconceptional period, fetal number and fetal sex on the development of the hypothalamo-pituitary-adrenal axis in sheep during late gestation. Biology of Reproduction 66 1562-1569. (https:// doi.org/10.1095/biolreprod66.5.1562)

Florini JR, Ewton DZ \& Magri KA 1991 Hormones, growth factors and myogenic differentiation. Annual Review of Physiology 53 201-216. (https://doi.org/10.1146/annurev.ph.53.030191.001221)
Forhead AJ \& Fowden AL 2014 Thyroid hormones in fetal growth and prepartum maturation. Journal of Endocrinology 221 R87-R103. (https:// doi.org/10.1530/JOE-14-0025)

Forhead AJ, Curtis K, Kapstein E, Visser TJ \& Fowden AL 2006 Developmental control of iodothyronine deiodinases by cortisol in the ovine fetus and placenta near term. Endocrinology 147 5988-5994. (https://doi.org/10.1210/en.2006-0712)

Fourie PD 1962 Growth and development of sheep. New Zealand Journal of Agricultural Research 5 190-222. (https://doi.org/10.1080/00288233.19 62.10419991)

Fowden AL \& Forhead AJ 2015 Glucocorticoids as regulatory signals during intrauterine development. Experimental Physiology 100 1477-1487. (https://doi.org/10.1113/EP085212)

Fowden AL \& Silver M 1995 The effects of thyroid hormones on oxygen and glucose metabolism in the sheep fetus during late gestation. Journal of Physiology 482 203-213. (https://doi.org/10.1113/jphysiol.1995. sp020510)

Fowden AL, Li J \& Forhead AJ 1998 Glucocorticoids and the preparation for life after birth: are there long-term consequences of the life insurance? Proceedings of the Nutrition Society 57 113-122. (https://doi.org/10.1079/ pns19980017)

Fowden AL, Valenzuela OA, Vaughan OR, Jellyman JK \& Forhead AJ 2016 Glucocorticoid programming of intrauterine development. Domestic Animal Endocrinology 56 (Supplement) S121-S132. (https://doi. org/10.1016/j.domaniend.2016.02.014)

Gnaiger E, Kuznetsov AV, Schneeberger S, Seiler R, Brandacher G, Steurer W \& Margreiter R 2000 Mitochondria in the cold. In Life in the Cold, pp. 431-442. Eds G Heldmaier \& MPP Klingenspor. Berlin: Springer.

Gnanalingham M, Hyatt M, Bispham J, Mostyn A, Clarke L, Budge H, Symonds M \& Stephenson T 2008 Maternal dexamethasone administration and the maturation of perirenal adipose tissue of the neonatal sheep. Organogenesis 4 188-194. (https://doi.org/10.4161/ org.4.3.6506)

Goffat S \& Wiesner RJ 2003 Regulation and co-ordination of nuclear gene expression during mitochondrial biogenesis. Experimental Physiology 88 33-40. (https://doi.org/10.1113/eph8802500)

Gyllenhammer LE, Entinger S, Buss C \& Wadhwa PD 2020 Developmental programming of mitochondrial biology: a conceptual framework and review. Proceedings of Biological Sciences $\mathbf{2 8 7}$ 20192713. (https://doi. org/10.1098/rspb.2019.2713)

Joseph S, Alvava B, Antolic A, Richards EM, Wood CE \& Keller-Wood M 2020 Fetal ovine skeletal and cardiac muscle transcriptomics are differentially altered by increased maternal cortisol during gestation. Physiological Genomics 52 178-190. (https://doi.org/10.1152/ physiolgenomics.00096.2019)

Kelly AK, Walters SM, McGee M, Fronseca RG, Carberry C \& Kenny DA 2011 mRNA expression of genes regulating oxidative phosphorylation in the muscle of beef cattle divergently ranked on residual feed intake. Physiological Genomics 43 12-23. (https://doi.org/10.1152/ physiolgenomics.00213.2009)

Khamoui AV, Desai M, Ross MG \& Rossiter HB 2018 Sex-specific effects of maternal and postweaning high-fat diet on skeletal muscle mitochondrial respiration. Journal of Developmental Origins of Health and Disease 9 670-677. (https://doi.org/10.1017/S2040174418000594)

Kimura S \& Rasmussen H 1977 Adrenal glucocorticoids, adenine nucleotide translocation and mitochondrial calcium accumulation. Journal of Biological Chemistry 252 1217-1225. (https://doi.org/10.1016/ S0021-9258(17)40643-0)

Kuznetsov AV, Veksler V, Gellerich FN, Saks V, Margreiter R \& Kunz WS 2008 Analaysis of mitochondrial function in situ in permeabilized muscle fibers, tissues and cells. Nature Protocols 3 965-976. (https://doi. org/10.1038/nprot.2008.61)

Lapp HE, Barlett AA \& Hunter RG 2019 Stress and glucocorticoid receptor regulation of mitochondrial gene expression. Journal of Molecular Endocrinology 62 R121-R128. (https://doi.org/10.1530/JME-18-0152) https://joe.bioscientifica.com https://doi.org/10.1530/JOE-21-0171 (c) 2021 The authors Published by Bioscientifica Ltd. Printed in Great Britain

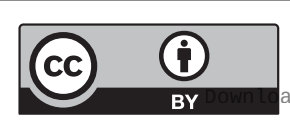

This work is licensed under a Creative Commons Attribution 4.0 International License.

Atrom Bioscientifica com at $04 / 26 / 2023$ 11:25:25AM 
Larsen S, Neilsen J, Hansen CN, Neilsen LB, Wibrand F, Stride N, Schroder HD, Boushel R, Helge JW, Dela F, et al. 2012 Biomarkers of mitochondrial content in skeletal muscle of healthy young human subjects. Journal of Physiology 590 3349-3360. (https://doi.org/10.1113/ jphysiol.2012.230185)

Lee SR, Kim HK, Song IS, Youm J, Dizon LA, Jeong SH, Ko TH, Heo HJ, Ko KS, Rhee BD, et al. 2013 Glucocorticoids and their receptors: insights into specific roles in mitochondria. Progress in Biophysics and Molecular Biology 112 44-54. (https://doi.org/10.1016/j.pbiomolbio.2013.04.001)

Lehman JJ, Barger PM, Kovacs A, Saffitz JE, Medeiros DM \& Kelly DP 2000 Peroxisome proliferator-activated receptor $\gamma$ co-activator-1 promotes cardiac mitochondrial biogenesis. Journal of Clinical Investigation 106 847-856. (https://doi.org/10.1172/JCI10268)

Liang H \& Ward WF 2006 PGC-1 $\alpha$ : a key regulator of energy metabolism. Advances in Physiology Education 30 145-151. (https://doi.org/10.1152/ advan.00052.2006)

Lombardi A, Moreno M, de Lange P, Iossa S, Busiello RA \& Goglia F 2015 Regulation of skeletal muscle mitochondrial activity by thyroid hormones: focus on the 'old' triiodothyronine and the 'emerging' 3.5-di-iodothronine. Frontiers in Physiology 6 237. (https://doi. org/10.3389/fphys.2015.00237)

Minai L, Martinovic J, Chretien D, Dumez F, Razavi F, Munnich A \& Rotig A 2008 Mitochondrial respiratory chain complex assembly and function during human fetal development. Molecular Genetics and Metabolism 94 120-126. (https://doi.org/10.1016/j.y mgme.2007.12.007)

Mostyn A, Pearce S, Stephenson T \& Symonds ME 2004 Hormonal and nutritional regulation of adipose tissue mitochondrial development and function in the newborn. Experimental and Clinical Endocrinology and Diabetes 112 2-9. (https://doi.org/10.1055/s-2004-815719)

Myers DA, Hanson K, mlynarczyk M, Kaushal KM \& Ducsay CA 2008 Long term hypoxia modulates expression of key genes regulating adipose function in the late-gestation ovine fetus. American Journal of Physiology 294 R1312-R1318. (https://doi.org/10.1152/ajpregu.00004.2008)

Nakai A, Shibazaki Y, Taniuchi Y, Oya A, Asakura H, Koshino T \& Araki T 2002 Effect of dexamethasone on mitochondrial maturation in the fetal rat brain. American Journal of Obstetrics and Gynecology 186 574-578. (https://doi.org/10.1067/mob.2002.121542)

Nunnari J \& Suomalainen A 2012 Mitochondria in sickness and health. Cell 148 1145-1159. (https://doi.org/10.1016/j.cell.2012.02.035)

Pesta D \& Gnaiger E 2012 High-resolution respirometry: oxphos protocols for human cells and permeabilized fibers from small biopsies of human muscle. Methods in Molecular Biology 810 25-58. (https://doi. org/10.1007/978-1-61779-382-0_3)

Picard M, McEwan BS, Epel ES \& Sandi C 2018 An energetic view of stress: focus on mitochondria. Frontiers in Neuroendocrinology 49 72-85. (https://doi.org/10.1016/j.yfrne.2018.01.001)

Prieur B, Bismuth J \& Delaval E 1998 Effects of adrenal steroid hormones on mitochondrial maturation during the late fetal period. European Journal of Biochemistry 252 194-199. (https://doi.org/10.1046/j.14321327.1998.2520194.x)
Rachamim N, Latter H, Malinin N, Asher C, Wald H \& Garty H 1995 Dexamethasone enhances expression of mitochondrial oxidative phosphorylation genes in the rat distal colon. American Journal of Physiology 269 C1305-C1310. (https://doi.org/10.1152/ ajpcell.1995.269.5.C1305)

Reddy PH, Manczak M, Yin X, Grady MC, Mitchell A, Kandimalla R \& Kurura CS 2016 Protective effects of a natural product, curcumin, against amyloid $\beta$ induced mitochondrial and synaptic toxicities in Alzheimer's disease. Journal of Investigative Medicine 64 1220-1234. (https://doi.org/10.1136/jim-2016-000240)

Reynolds RM 2013 Programming effects of glucocorticoids. Clinical Obstetrics and Gynecology 56 602-609. (https://doi.org/10.1097/ GRF.0b013e31829939f7)

Rodriguez-Cano AM, Calzada-Mendoza CC, Estrada-Gutierrez G, MendozaOrtega JA \& Perichart-Perera O 2020 Nutrients, mitochondrial function and perinatal health. Nutrients 12 2166. (https://doi.org/10.3390/ nu12072166)

Rog-Zielinska EA, Craig MA, Manning JR, Richardson RV, Gowans GJ, Dunbar DR, Gharbi K, Kenyon CJ, Holmes MC, Hardie DG, et al. 2015 Glucocorticoid promote structural and functional maturation of fetal cardiomyocytes: a role for PGC1 $\alpha$. Cell Death and Differentiation 22 1106-1116. (https://doi.org/10.1038/cdd.2014.181)

Schmittgen TD \& Livak KJ 2018 Analyzing real-time PCR data by comparative C-T methods. Nature Protocols 3 1101-1108. (https://doi. org/10.138/nprot2008.73)

Snyder JM, Rodgers HF, O’Brien JA, Mahli N, Magliato SA \& Durham PL 1992 Glucocorticoid effects on rabbit fetal lung maturation in vivo: an ultrastructural morphometric study. Anatomical Record 232 133-140. (https://doi.org/10.1002/ar.1092320115)

Sparks LM, Gemmink A, Phielix E, Bosma M, Schaart G, MoonenKornips E, Jorgensen JA, Nascimento EBM, Hesselink MK, Schrauwen P, et al. 2016 ANT1-mediated fatty acid-induced uncoupling as target for improving myocellular insulin sensitivity. Diabetologia 59 1030-1039. (https://doi.org/10.1007/s00125-016-3885-8)

Vaughan OR, Davies KL, Ward JW, DeBlasio MJ \& Fowden AL 2016 A physiological increase in maternal cortisol alters uteroplacental metabolism in pregnant ewes. Journal of Physiology 594 6407-6418.

Walker DW \& Luff AR 1995 Functional development of fetal limb muscles: a review of the roles of activity, nerves and hormones. Reproduction, Fertility, and Development 7 391-398. (https://doi.org/10.1071/rd9950391)

Weber K, Bruck P, Mikes Z, Kupper JH, Klingenspor M \& Weisner RJ 2002 Glucocorticoid hormone stimulates mitochondrial biogenesis specifically in skeletal muscle. Endocrinology 143 177-184. (https://doi. org/10.1210/endo.143.1.8600)

Yates DT, Caderet CN, Beede KA, Roley HE, Macko AR, Amerson MJ, Camacho LE \& Limesand SW 2016 Intrauterine growth-restricted sheep fetuses exhibit smaller hindlimb fibers and lower proportions of insulin-sensitive type I fibers near term. American Journal of Physiology: Regulatory, Integrative and Comparative Physiology 310 R1020-R1029. (https://doi.org/10.1152/ajpregu.00528.2015)

Received in final form 15 July 2021

Accepted 27 July 2021

Accepted Manuscript published online 29 July 2021 https://joe.bioscientifica.com https://doi.org/10.1530/JOE-21-0171 (c) 2021 The authors Published by Bioscientifica Ltd. Printed in Great Britain

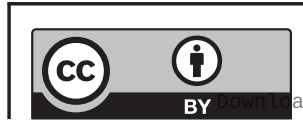

This work is licensed under a Creative Commons Attribution 4.0 International License. ded from Bioscientifica.com at 04/26/2023 11:25:25AM 